\title{
Uma revisão sobre: tratamento biológico de drenagem de mina - cenário atualizado, perspectivas e recomendações de futuros trabalhos
}

\author{
Biological treatment of mine drainage - scenario updated, perspectives, \\ and recommendations for future works
}

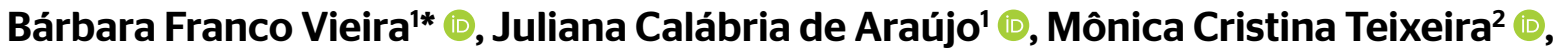 \\ Josiane Caroline de Souza Pereira² ${ }^{2}$
}

\begin{abstract}
RESUMO
Rochas contendo sulfetos metálicos podem ser oxidadas em um processo catalisado por procariotos quimiolitoautotróficos ou $\mathrm{Fe}^{3+}$. A atividade mineradora acelera esse processo ao gerar resíduos contendo sulfetos metálicos com grande superfície de contato. O lixiviado resultante, conhecido como drenagem de mina (DM), é rico em sulfato, íons hidrogênio e contaminantes químicos inorgânicos como ferro (Fe), zinco (Zn), cádmio (Cd), manganês (Mn), níquel (Ni), arsênio (As) e alumínio (Al). Para remover tais poluentes, atualmente, o principal tratamento utilizado é a adição de reagentes alcalinos. Entretanto, esse método tem limitada eficiência, alto custo e gera grandes volumes de resíduos sólidos tóxicos de relativa solubilidade. Bactérias redutoras de sulfato (BRS) podem oxidar matéria orgânica com geração de sulfeto. Algumas vias metabólicas do processo consomem $\mathrm{H}^{+}$ neutralizando o pH. O sulfeto produzido pode reagir com contaminantes inorgânicos e precipitá-los, permitindo sua recuperação da fase líquida. O uso de subprodutos industriais e urbanos contendo diferentes fontes de carbono como doadores de elétrons no tratamento de DM tem sido investigado. Este artigo sumariza dados sobre as variáveis relevantes para a atividade microbiana durante o tratamento biológico de DM, analisando o atual cenário de pesquisas com fontes alternativas de carbono. Discute-se ainda novas fontes de matéria orgânica ainda não aplicadas para tratamento biológico de efluentes e que, sob aspectos de sustentabilidade, dos pontos de vista sustentável e econômico, podem ser usadas no tratamento de resíduos.
\end{abstract}

Palavras-chave: bactérias redutoras de sulfato; drenagem de mina; doadores de elétrons; resíduo de cervejaria; glicerol bruto; sustentabilidade.

\begin{abstract}
Rocks containing metal sulfides be can oxidized biologically or chemically. Chemolithoautotrophics prokaryotes and $\mathrm{Fe}^{3+}$ catalyze this process. The mining activities also accelerate the process for creates metal sulphides tailings with a big contact surface. The leached formed is called Mine Drainage (MD) whose composition is rich in sulphate, hydrogen ions and inorganic chemical contaminants such as Fe, Zn, Mn, Cd, Ni, As e Al. Currently, in order to remove these pollutants, the main treatment used is the addition of alkaline reagents. However, the method has limited efficiency, high cost with input reagents and generates wide amounts of toxic solid residues with high solubility. The sulphide reducing bacterias (RSB) can oxidize organic matter generating sulphide. Some metabolic pathways consume $\mathrm{H}+$ neutralizing the $\mathrm{pH}$. The sulphide formed can react and precipitate inorganic pollutants, allowing their recuperation from the liquid phase. The use of industrial and urban by-products containing different carbon sources have been investigated as an electron donor in the MD treatment. The diverse microbial consortia synergic acting can present bigger efficiency in the presence of mixed carbon sources, besides lower cost in relation to the pure matter. Here will be detailed the biological treatment about which and how the variables of the system can influence the microbial activity and relevant molecules to the treatment. After is described the current situation of the research about alternative carbon sources. New carbon sources whose are a by-product of the expanding industry presenting good feature to anaerobic degrading are suggested. The by-product potential is described from the point of view of sustainability, and waste management.
\end{abstract}

Keywords: sulfate reducing bacteria; mina drainage; electron donor; brewery waste; crude glycerol; sewage; sustainability.

\section{INTRODUÇÃO}

A drenagem de mina (DM) é um efluente rico em sulfato que tem origem em processos químicos e biológicos naturais intensificados na atividade mineradora em que são estocadas pilhas de rejeitos de minérios associados a sulfetos. A DM ocorre por oxidação de minerais sulfetados, formando sulfatos dissolvidos e íons $\mathrm{H}^{+}$. Estes, por sua vez, são responsáveis pelo abaixamento de $\mathrm{pH}$ e pela

'Universidade Federal de Minas Gerais - Belo Horizonte (MG), Brasil.

2Universidade Federal de Ouro Preto - Ouro Preto (MG), Brasil.

*Autora correspondente: franco.barbara@hotmail.com

Conflitos de interesse: os autores declaram não haver conflito de interesses.

Financiamento: Conselho Nacional de Desenvolvimento Científico e Tecnológico (CNPq).

Recebido: 18/04/2019 - Aceito: 21/10/2019 - Reg. ABES: 20190123 
solubilização de elementos inorgânicos como arsênio (As), chumbo $(\mathrm{Pb})$, alumínio (Al), cádmio (Cd), zinco (Zn), cobre (Cu) e cromo (Cr) (LIN et al., 2018). A velocidade de geração de DM e sua composição são variáveis em razão da influência de vários fatores como $\mathrm{pH}$, temperatura, quantidade de oxigênio, água, concentração de $\mathrm{Fe}^{3+}$, microrganismos quimiolitoautotróficos, que catalisam a geração de DM e a superfície de contato dos sulfetos metálicos com os fatores envolvidos (KEFENI; MSAGATI; MAMBA, 2017).

Atualmente, o principal mecanismo de tratamento de DM utilizado é a adição de reagentes alcalinos com limitada eficiência quanto à remoção de poluentes solúveis. O volumoso precipitado de hidróxido metálico com carbonatos é tóxico, de alta solubilidade e dificilmente adequado para a recuperação de metais (SIMATE; NDLOVU, 2014).

O tratamento biológico com bactérias redutoras de sulfato (BRS) não demanda adição contínua de insumos neutralizantes e pode ser alcançado em baixos valores de $\mathrm{pH}$, pressão e temperatura ambientes e tanques de agitação convencionais (KEFENI; MSAGATI; MAMBA, 2017). O tratamento com BRS possibilita a remoção do sulfato dissolvido com geração de alcalinidade e precipitação e recuperação de metais. Águas residuárias e resíduos sólidos orgânicos podem proporcionar a condição redox adequada às espécies do consórcio anaeróbio que promovem a redução de sulfato (WENDT-POTTHOFF; NEU, 1998). Entre as fontes de carbono já testadas no tratamento biológico de DM, têm-se esgoto doméstico, esterco animal, serragem, casca de cereais, soro de leite, vinhaça, lodo de esgoto e resíduos sólidos municipais (HAO et al., 2014; JAMIL; CLARKE, 2013; KEFENI; MSAGATI; MAMBA, 2017; KUMAR et al., 2015; KUMAR et al., 2011; MOCKAITIS et al., 2014; MOODLEY et al., 2017; PLACE; FIGUEROA; WILDEMAN, 2006). Tais pesquisas mostram que o uso de substratos mistos, além de conferir vantagens econômicas, pode também favorecer a redução de sulfato.

O destino do trub resíduo da produção de cerveja também compõe um amplo campo de pesquisa como substrato misto para tratamento de DM. O trub é rico em açúcares (PERIMENIS et al., 2018), o que pode conferir potencial como substrato de consórcios anaeróbios. Ainda acerca de substratos mistos, tem-se, atualmente, grande crescimento na produção mundial de biodiesel, o que abre um amplo campo de pesquisa para encontrar novas aplicações para o glicerol residual produzido (QUISPE; CORONADO; CARVALHO JÚNIOR, 2013). O glicerol puro já foi amplamente investigado no tratamento biológico de DM, porém o produto impuro apresenta complexidades que podem interferir no tratamento. A redução biológica de sulfato já avaliada com oxidação de glicerol bruto (GB) não se aplica às condições da DM com, por exemplo, baixa concentração de sulfato (ZAMZOW; TSUKAMOTO; MILLER, 2007; MORA; LAFUENTE; GABRIEL, 2018), ou aplicada em outro ambiente, como campos de petróleo (SANTOS et al., 2015).

O objetivo desta revisão foi a reunião e a discussão crítica de informações e questionamentos sobre as tecnologias disponíveis para o tratamento de DM, de modo a nortear as próximas pesquisas em direção a um tratamento mais sustentável, mais eficiente, proporcionando um destino adequado a subprodutos e efluentes. Para tanto, será detalhado o perfil de diferentes substratos orgânicos com potencial de aplicabilidade como fonte de carbono para redução de sulfato. Também serão apurados os fatores do sistema, que são importantes para aplicação da técnica, especialmente em escala plena. Será avaliada também a pertinência e o potencial de resíduos ainda não utilizados no tratamento de DM.

\section{Redução biológica de sulfato e fatores intervenientes}

$\mathrm{O}$ processo biológico consiste na redução anaeróbia de sulfato $\left(\mathrm{SO}_{4}^{2-}\right) \mathrm{com}$ consumo de elétrons provenientes de um substrato orgânico ou $\mathrm{H}_{2}$. Embora a hidrólise e a precipitação de alguns minerais liberem prótons, há elevação do $\mathrm{pH}$ por meio da liberação de íons $\mathrm{HCO}_{3}{ }^{-}$somada ao consumo de prótons durante a redução de sulfato (LIN et al., 2018). O sulfeto produzido, $\mathrm{H}_{2} \mathrm{~S}$ (g), tem afinidade química com alguns cátions metálicos, precipitando-os como sulfetos metálicos de baixa solubilidade, em uma ampla faixa de $\mathrm{pH}$. A recuperação de metais de interesse pode ser realizada por precipitação seletiva (HEDRICH; JOHNSON, 2014).

A respeito da influência que as condições do meio exercem sobre a redução biológica de sulfato, Dev, Roy e Bhattacharya (2017) citam, em ordem de importância, o pH, a relação volume-volume entre a fonte de carbono e a DM, a concentração de sulfato, o tempo de detenção hidráulica (TDH) e, por último, a demanda química de oxigênio (DQO). Com base em resultados gerados em diferentes pesquisas, construiu-se a Tabela 1 , sobre as variáveis de influência na atividade das BRS.

A presença de oxigênio também pode interferir, mas dificilmente é objeto de avaliação nas pesquisas sobre tratamento de DM. É inclusive proposto que se padronize a lavagem do gás para os testes (SERRANO et al., 2020). Alguns dos fatores de interferência na atividade das BRS serão detalhados a seguir.

\section{Oxigênio}

Na maioria das pesquisas com BRS e DM, a influência do $\mathrm{O}_{2}$ não é investigada. Para a escala plena, a ausência completa de $\mathrm{O}_{2}$ pode ser dispendiosa ou até inviável. Apesar de ser um grupo anaeróbio, as BRS apresentam alguma resistência ao oxigênio, podendo ser encontradas ativas em condições temporariamente aeróbias, elaborando estratégias como o deslocamento dos organismos para regiões anóxicas, a criação de microambientes anóxicos por meio de granulação e sistemas enzimáticos que fazem a redução e a eliminação do $\mathrm{O}_{2}$ (KJELDSEN; JOULIAN; INGVORSEN, 2004). Mora, Lafuente e Gabriel (2018) constataram que a presença de oxigênio tornou a sulfetogênese mais lenta, porém, de forma geral, favoreceu-a em detrimento da metanogênese. A possibilidade de microaeração é corroborada por Vieira et al. (2016) e Matos et al. (2018), que

Tabela 1 - Condições ideais e de tolerância para atividade das bactérias redutoras de sulfato.

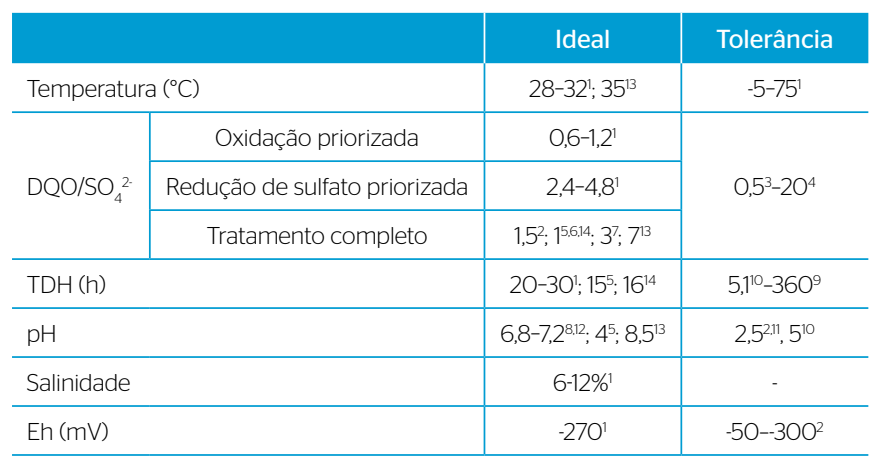

DQO: demanda química de oxigênio; TDH: tempo de detenção hidráulica; 'Hao et al. (2014); ${ }^{2}$ Dev, Roy e Bhattacharya (2017); ${ }^{3}$ Silva et al. (2002); ${ }^{4} \mathrm{Hu}$ et al. (2015); ${ }^{5}$ Vieira et al. (2016); ${ }^{6}$ Rodriguez (2010); ${ }^{7}$ Matos et al. (2018); ${ }^{8}$ Hussain e Qazi (2016); ${ }^{9}$ Martins et al. (2010); ${ }^{10}$ Jamil e Clarke (2013); "Bertolino et al. (2014); ${ }^{12} \mathrm{Nagpal}$ et al. (2000);

${ }^{13}$ Mora, Lafuente e Gabriel (2018); ${ }^{14}$ Cunha et al. (2020).

Fonte: elaborada pelas autoras (2019) 
não avaliando anaerobiose completa, obtiveram remoção satisfatória de sulfato. Como se trata de uma configuração que apresenta facilidades econômicas e operacionais, é válido dispensar a anaerobiose no tratamento biológico de DM.

\section{Relação $\mathrm{DQO} / \mathrm{SO}_{4}{ }^{2 \cdot}$}

Quanto à proporção entre o doador de elétrons e a concentração de sulfato, quando pequenas quantidades de doadores de elétrons são utilizadas, a quantidade de nutriente fornecida pode ser insuficiente para a manutenção do consórcio microbiano. Por outro lado, quando o doador de elétrons contém também nutrientes e é adicionado em excesso, pode haver acúmulo de amônia, prejudicando a eficiência do tratamento (DEV; ROY; BHATTACHARYA, 2017). No que diz respeito ao sulfato, pequenas concentrações desse íon estimulam o desenvolvimento de organismos que competem com as BRS. Já em elevadas concentrações, ocorre grande produção de sulfeto, e o excesso desse, por sua vez, afeta negativamente a atividade das BRS (KEFENI; MSAGATI; MAMBA, 2017).

Vieira et al. (2016) constataram que, quando há maior disponibilidade de elétrons que a demanda para redução do sulfato presente, ou seja, com relação DQO/ $/ \mathrm{SO}_{4}{ }^{2-}$ maior que 0,67 , há boa remoção de sulfato e $100 \%$ de remoção de DQO. Isso sugere que a oxidação da matéria orgânica ocorra por diferentes vias, além da sulfetogênese, como metanogênese e redução de íons metálicos, o que minimiza o acúmulo de intermediários metabólicos prejudiciais ao inóculo. $\mathrm{O}$ excesso de matéria orgânica direcionada à redução de íons como $\mathrm{Fe}^{\mathrm{III}}$ ou $\mathrm{As}^{\mathrm{V}}$ leva à biomineralização de sulfetos metálicos, como de ferro (Fe), zinco (Zn) e arsênio (As) (RODRIGUEZ-FREIRE et al., 2016). Uma relação $\mathrm{DQO} / \mathrm{SO}_{4}{ }^{2-}$ acima de 0,67 também pode favorecer o tratamento por diminuição dos efeitos inibidores de alguns tóxicos, como corroborado por Matos et al. (2018), que mostram que os efeitos de As ${ }^{\mathrm{III}}$ são maiores em menores relações $\mathrm{DQO} / \mathrm{SO}_{4}{ }^{2-}$. No entanto, em reatores de leito fluidizado de fluxo ascendente, menores valores de $\mathrm{DQO} / \mathrm{SO}_{4}^{2-}$ podem ser mantidos com o objetivo de evitar a ruptura do leito de lodo e a lavagem do leito de lodo por geração de metano (CORBETT, 2001). A definição da melhor relação $\mathrm{DQO} / \mathrm{SO}_{4}{ }^{2-}$ deve ser feita de acordo com o objetivo e o tipo de reator.

\section{$\mathrm{pH}$}

Em pH básico, o acetato não é consumido na sulfetogênese, o qual acumulado pode inviabilizar o tratamento biológico de DM. Sob baixo $\mathrm{pH}$, a concentração de prótons, ácidos orgânicos e sulfeto afeta a redução de sulfato. O sulfeto em $\mathrm{pH}$ baixo se encontra na forma $\mathrm{H}_{2} \mathrm{~S}$, que tem passagem pela membrana celular. O sulfeto pode se combinar com $\mathrm{Fe}$, citocromo ou compostos contendo metais, afetando suas funcionalidades no metabolismo. Em baixo pH, os microrganismos desviam energia disponível para o crescimento no bombeamento ativo de prótons para fora da célula (SÁNCHEZ-ANDREA et al., 2014).

Quanto aos ácidos orgânicos, 50\% do lactato, por exemplo, em pH 3 está na forma ácida, e o ácido lático pode se difundir nas células, implicando também em perda energética no bombeamento de prótons. Em pH inferior a 4,75, a forma dominante do acetato é o ácido acético, altamente tóxico para a maioria dos microrganismos, incluindo os acidófilos. Foi obtido 50\% de inibição de crescimento em uma cultura BRS mista em pH 6,2, com 0,9 mM de ácido acético não dissociado com concentração total de $25 \mathrm{mM}$ (REIS et al., 1990). Porém, quando as espécies metanogênicas estão ativas, elas podem metabolizar o acetato.

Em contraponto às desvantagens do baixo $\mathrm{pH}$, a energia livre de Gibbs da redução de sulfato em baixos pHs é maior, podendo permitir, assim, o crescimento das células, nessa condição. Outros mecanismos, como a expulsão de vesículas contendo $\mathrm{H}^{+} \mathrm{e}$ o aproveitamento da força motriz do deslocamento de prótons para produção de ATP, podem ocorrer (SÁNCHEZ-ANDREA et al., 2014). A toxicidade das formas predominantes de ácidos orgânicos explica por que substratos não iônicos, como glicerol, hidrogênio, álcoois ou açúcares, são mais convenientes para sistemas em baixo $\mathrm{pH}$.

\section{Tempo de detenção hidráulica}

Quanto ao TDH, esse apresenta variações bastante significativas, inclusive com o uso dos mesmos substratos, como mostra a Tabela 2. O TDH ideal varia conforme o substrato, a configuração operacional e de mistura, a matriz imobilizadora e o objetivo do tratamento (HAO et al., 2014). Culturas puras demandam maiores valores de TDH na degradação de substratos complexos, como aplicado por Hussain e Qazi (2016).

\section{Elementos tóxicos}

Diferentes autores apresentam valores distintos para a concentração de elementos tóxicos que afeta a redução de sulfato, os quais são mostrados na Tabela 3. Os diferentes valores apresentados entre os estudos podem ocorrer em razão de diferenças no $\mathrm{pH}$. A fonte de carbono pode diluir ou neutralizar elementos tóxicos (MATOS et al., 2018), como também conter ou levar à formação de outros produtos tóxicos (ALBUQUERQUE, 2014).

\section{Fonte de carbono}

As BRS possuem capacidade de metabolizar uma grande variedade de doadores de elétrons, ácidos carboxílicos, álcoois, açúcares, compostos aromáticos, monóxido de carbono, metano e aminoácidos (HAO et al., 2014). Substratos mistos são recomendados para o crescimento do consórcio, em que o resíduo metabólico de uma espécie se torna substrato de outra (NECULITA; ZAGURY, 2008). Iniciar o tratamento biológico com uma fonte de carbono simples e facilmente degradável e, em seguida, substitui-la por fonte de carbono mista foi sugerido por Beaulieu et al. (2000) e confirmado por Muhammad et al. (2015) como opção para melhorar a taxa de redução de sulfato e metais.

Resíduos e águas residuárias com poluentes orgânicos podem favorecer a neutralização da acidez e a adsorção de elementos da DM potencialmente tóxicos às BRS, além do aporte de macro e micronutrientes (DEV; ROY; BHATTACHARYA, 2017). Esgoto doméstico, por exemplo, pode diluir a DM,

Tabela 2 - Variações no tempo de detenção hidráulica em reatores de remoção biológica de sulfato.

\begin{tabular}{l|c|c|c} 
TDH (h) & Substrato & Reator & Referência \\
\hline 5,1 & Etanol & Leito fluidizado & Nagpal et al. (2000) \\
\hline 15 & Etanol & Batelada & Vieira et al. (2016) \\
\hline 16 & Etanol & Leito fluidizado & Cunha et al. (2020) \\
\hline 10 & Lactato & Leito fluidizado & Bertolino et al. (2012) \\
\hline 240 & Glicerol & Leito estruturado & Matos et al. (2018) \\
\hline 48 & $\begin{array}{c}\text { Extrato resíduo } \\
\text { marinho }\end{array}$ & Leito fixo & Dev, Roy e \\
\hline 16 & Vinhaça & $\begin{array}{c}\text { Leito fixo-estruturado } \\
\text { e fluxo descendente }\end{array}$ & Nogueira et al. (2019) \\
\hline
\end{tabular}

TDH: tempo de detenção hidráulica.

Fonte: elaborada pelas autoras (2019) 
minimizando toxicidade e possíveis choques de cargas causadas pela heterogeneidade e pela composição flutuante da DM (SMYNTEK et al., 2018).

Resíduos lignocelulósicos também auxiliam no controle da compactação da biomassa e, consequentemente, de curtos-circuitos, por favorecer a permeabilidade em reatores de fluxo contínuo (SKOUSEN et al., 2017). Na Tabela 4 são apresentados estudos sobre diferentes fontes de carbono e misturas. Diante do exposto, é possível considerar o potencial que os substratos mistos têm para remoção de sulfato e metais. Nessa tabela, é demonstrado que a redução da DQO dificilmente é avaliada, tal como a formação, o consumo e o acúmulo de intermediários metabólicos orgânicos. Quando esse parâmetro for avaliado simultaneamente à redução de sulfato, as menores remoções de sulfato, que são mostradas, podem ser compreendidas e o processo mais bem aproveitado.

\section{Tratamento biológico de drenagem de mina com glicerol}

A redução de sulfato pode ocorrer pela completa oxidação do glicerol a $\mathrm{CO}_{2}$ ou pela oxidação incompleta a acetato e $\mathrm{CO}_{2}$ (SANTOS; JOHNSON, 2018). Bactérias fermentativas podem formar, a partir da degradação de glicerol, componentes-chave na degradação sinérgica, como hidrogênio e formiato, que são excelentes doadores de elétrons para redutoras de sulfato, como o gênero Desulfomicrobium. Diferentes condições sob as quais o glicerol puro já foi aplicado na redução de sulfato são sumarizadas na Tabela 5 .

Observa-se, pela Tabela 5, que o tipo e a concentração de ácido graxo acumulado podem variar com o mesmo doador de elétrons, quando em diferentes condições. A degradação de glicerol em pH 7 gera acetato, e em pH 4, além de acetato, lactato e 1.3-propanodiol. O acúmulo de intermediários metabólicos pode estar mais relacionado com seu consumo do que a concentração inicial de DQO. Na pesquisa de Ňancucheo e Johnson (2014), foi constatado que o acúmulo de ácido acético não foi diretamente proporcional à concentração inicial de glicerol.
A produção de biodiesel é crescente por este ser biodegradável, renovável, não tóxico, pobre em enxofre e, em relação aos combustíveis fósseis, exercer menor influência na aceleração do aquecimento global, menor emissão de HC e CO (QUISPE; CORONADO; CARVALHO JÚNIOR, 2013).

Do volume de biodiesel sintetizado, entre 10 e $20 \%$ é produzido de glicerol como subproduto (QUISPE; CORONADO; CARVALHO JÚNIOR, 2013). A produção de bioetanol também gera, em média, 10\% da massa de açúcar utilizada de glicerol (ALBUQUERQUE, 2014). O teor de glicerol no subproduto desmetilado é entre 70 e $88 \%$, e no metilado entre 50 e $70 \%$ (QUISPE; CORONADO; CARVALHO JÚNIOR, 2013). As concentrações das impurezas variam conforme a matéria-prima utilizada e se distribuem entre água, sais, ésteres, álcool e óleo residual (ALBUQUERQUE, 2014).

O GB foi bem menos investigado como doador de elétrons na redução de sulfato. Por isso, não é suficiente para esclarecer completamente as condições de seu uso no tratamento de DM. A complexidade da porção não glicerol dessa mistura pode conferir interferências no sistema de tratamento, as quais permanecem como lacunas de conhecimento sobre seu uso junto às BRS. Algumas moléculas orgânicas podem promover inibição da atividade, como aldeídos, acroleína e formaldeído, assim como metais que podem estar presentes. O GB também pode apresentar íons sódio entre 0,36 e 19 g.L.-1 e potássio entre 0,08 e 92 g.L.- . A concentração inibitória de $\mathrm{Na}^{+}$é entre 3 e 16 e de $\mathrm{K}^{+}$entre 2 e 12 g.L.-1 (SANTOS et al., 2015). Como o glicerol possui DQO elevada, 1.122,80 g.L $\mathrm{L}^{-1}$ (ALBUQUERQUE, 2014), a diluição promovida com a DM para as relações $\mathrm{DQO} / \mathrm{SO}_{4}{ }^{2-}$ utilizadas no tratamento biológico deve tornar as concentrações desses íons insuficientes para inibição. A composição das formas orgânicas presentes no glicerol advindo de matérias-primas distintas é fornecida por Santos et al. (2015) e apresentada na Tabela 6.

As pesquisas que utilizam o GB na redução de sulfato (MORA; LAFUENTE; GABRIEL, 2018; SANTOS; JOHNSON, 2017) não se aplicam às condições de

Tabela 3 - Compostos e concentrações $\left(\mathrm{mg}^{\mathrm{L}} \mathrm{L}^{-1}\right)$ nas quais foi reportada toxicidade às bactérias redutoras de sulfato.

\begin{tabular}{c|c|c|c|c|c|c|c|c} 
Cu & Cd & Ni & Zn & Cr & Pb & Hg & Sulfeto & Referência \\
\hline $2-50$ & 4 & 10 & 13 & 60 & 75 & 74 & Jamil e Clarke (2013) \\
\hline 4 & 11 & 13 & 16,5 & 35 & 80 & - & $60-70$ & Hao et al. (2014) \\
\hline
\end{tabular}

Fonte: elaborada pelas autoras (2019).

\begin{tabular}{|c|c|c|c|c|c|}
\hline Matéria orgânica & Sulfato & DQO & Metais & $\mathrm{pH}$ & Referência \\
\hline Bagaço de cana & 100 & NM & NM & NM & Hussain e Qazi (2016) \\
\hline Extrato de resíduos marinhos & 98,3 & NM & 95 (Fe, Cu, Zn, Mg e Ni) & NM & Dev, Roy e Bhattacharya (2017) \\
\hline Palha de arroz (in situ) & 94 & NM & $100 \mathrm{Cu}$ & De 1 para 7 & Wu et al. (2010) \\
\hline Concha de mexilhão e composto fúngico & 39 & NM & $100 \mathrm{Al}$ e Zn & De 3,1 para 7,1 & Moodley et al. (2017) \\
\hline Chorume & 73,8 & NM & De 80 a 99 (Co, Cu, Fe, Zn e Ni) & NM & Moodley et al. (2017) \\
\hline Concha de mexilhão & - & NM & 98 (Fe, Zn, Al e Ni) & De 2,8 para 6,9 & Moodley et al. (2017) \\
\hline Efluente de fábrica de vinho & 90 & NM & $61 \mathrm{Fe}, 91 \mathrm{Zn} \mathrm{e} 97 \mathrm{Cu}$ & NM & Moodley et al. (2017) \\
\hline Conchas intemperizadas de mexilhão & NM & NM & 98 (Fe, Al, Zn e Ni) $22 \mathrm{Mn}$ & De 3 para 8 & Weber, Weisener e Diloreto (2015) \\
\hline Esterco de galinha & 79 & NM & 100 Cd, 97 Cu, 90 Zn, 94 Ni, 59 Mn e 86 Fe & NM & Zhang e Wang (2016) \\
\hline Esterco de vaca & 65 & NM & 100 Ca, 97 Cu, 84 Zn, 100 Ni, 67 Mn e 96 Fe & NM & Zhang e Wang (2016) \\
\hline Vinhaça de cana-de-açúcar & 96 & 100 & $95 \mathrm{Fe}$ & NM & Mockaitis et al. (2014) \\
\hline Pó de serra & 50 & NM & 79 Ca, 33 Cu, 88 Zn, 68 Ni, 95 Mn e 58 Fe & NM & Zhang e Wang (2016) \\
\hline
\end{tabular}

DQO; demanda química de oxigênio; NM: não mencionado.

Fonte: elaborada pelas autoras (2019). 
tratamento de DM, pois têm outros objetivos. A investigação de Santos et al. (2015) foi realizada em um poço de petróleo, e a de Behrooz e Borden (2012), junto aos rejeitos sólidos da mineração. A condição utilizada na pesquisa de Zamzow, Tsukamoto e Miller (2007), com 900 mg.L $\mathrm{L}^{-1}$, não reflete a condição da maioria das DM. Porém, uma importante constatação da pesquisa é que o inóculo aclimatado à fonte de carbono usa os intermediários metabólicos da degradação do glicerol mais completamente do que o fazem com o acetato produzido com a oxidação do etanol. Isso reforça o que os autores Beaulieu et al. (2000), Reisman, Gusek e Bishop (2003) mencionam sobre o uso de fontes mistas de carbono favorecer o tratamento. Em relação à quantidade de DQO destinada à sulfetogênese, o GB foi selecionado como a fonte de carbono mais adequada em relação ao acetato, ao soro de queijo, aos dejetos de suínos e à vinhaça (MORA; LAFUENTE; GABRIEL, 2018). As condições em que essa aplicação ocorreu são contempladas na Tabela 7.

Os resultados revelam que o GB pode ser vantajoso para a eficiência do tratamento em relação ao glicerol puro. A pesquisa de Santos et al. (2015) mostrou que após o período de aclimatação com start-up mais lento, a sulfetogênese com GB foi similar à ocorrida com glicerol puro. Os dados apresentados mostram que o GB pode ser mais sustentável como fonte de carbono no tratamento biológico de $\mathrm{DM}$, proporcionando menor custo ao tratamento enquanto confere um destino adequado ao resíduo.

\section{Resíduos da indústria cervejeira: potencial e pertinência de uso no tratamento biológico de drenagem de mina}

Não foram encontrados trabalhos na literatura que tenham usado resíduos de cervejaria como fonte de carbono para redução de sulfato. São produzidos como resíduos da produção de cerveja grãos gastos, trub da produção de mosto e resíduos de levedura (PERIMENIS et al., 2018). A composição dos resíduos de cervejaria é apresentada na Tabela 8.

O processo de cocção, que antecede a formação de trub, favorece a diminuição da cristalinidade, o aumento da área superficial e a liberação de açúcares. A presença de substâncias prontamente digeríveis e a menor concentração de hemicelulose podem ser a razão da rápida cinética metanogênica desse resíduo. A digestão anaeróbia de trub tem sido estudada para produção de produtos de valor econômico, como metano, carboxilato e bio-hidrogênio.

Perimenis et al. (2018) avaliaram metanogênese e acidogênese a partir dos resíduos agroindustriais polpa de pera, maçã e tâmara, após extração de suco, trub, levedura e grãos usados de cervejaria. $\mathrm{O}$ trub revelou o maior potencial de metano e as maiores concentrações de ácidos graxos voláteis totais durante a conversão acidogênica, principalmente ácido acético, ácido butírico e ácido caproico. O trub apresentou a maior produção de ácido caproico (45\%) que pode ser separado e aproveitado como produto de valor comercial em razão de suas possíveis aplicações finas. O ácido caproico tem maior número de carbonos e pode ser separado da água. Por conseguinte, os resíduos de cervejaria merecem mais investigação e apresentam considerável potencial como doadores de elétrons.

\section{CONCLUSÕES}

Acerca da aplicabilidade dos modelos de estudo em escala plena, os trabalhos mencionados mantêm uma concentração inicial de sulfato e metais constante. Porém, essa estabilidade não representa a realidade da geração de DM. Entre um local e outro, a composição da DM pode variar significativamente, como de 50 a 50.000 mg.L $L^{-1}$ de sulfato nas minas de Mina de Campbell e Nordic Elliot Lake, respectivamente, ou de 0 a $80 \mathrm{mg} \cdot \mathrm{L}^{-1}$ de As em Campbell e Heath Steele, respectivamente (MCGREGOR; BLOWES, 2002). Variações bastante significativas na concentração de poluentes também podem ocorrer em dois pontos de coleta da mesma mina ou em diferentes períodos, como detectado por Silvas et al. (2011) em um mesmo ponto de coleta de uma mina de Santa Catarina: em outubro e dezembro com 11.820 e 67,5 mg. $\mathrm{L}^{-1}$ de alumínio (Al) e pH 1,92 e 6, respectivamente. Nas pesquisas, é preciso considerar as grandes variações na composição das DM entre si e ao longo do tempo.

Tabela 6 - Composição química do glicerol bruto proveniente de diferentes matérias-primas, em mg. $\mathrm{mL}^{-1}$.

\begin{tabular}{l|c|c|c|c} 
Substância & Mamona & Algodão & $\begin{array}{c}\text { Óleose } \\
\text { gorduras }\end{array}$ & Soja \\
\hline Glicerol & 20,98 & 2,57 & 41,87 & 2,66 \\
\hline Formaldeído & 0,12 & - & 0,05 & - \\
\hline Acetaldeído & 1,26 & 0,11 & 0,70 & 0,03 \\
\hline Acroleína & 0,10 & 0,23 & 0,18 & 12,6 \\
\hline Propionaldeído & - & 0,63 & 0,19 & 0,1 \\
\hline Butiraldeído & - & 0,31 & 0,16 & 0,06 \\
\hline Benzaldeído & - & 0,51 & - & - \\
\hline Isovaleraldeído & - & 0,22 & 0,11 & - \\
\hline Valeraldeído & - & 1,7 & 0,52 & 0,21 \\
\hline O-tolualdeído & - & 0,17 & 0,15 & - \\
\hline M-tolualdeído & 0,2 & 0,58 & - & 0,08 \\
\hline
\end{tabular}

Fonte: Santos et al. (2015).

Tabela 5 - Condições e resultados de aplicações de glicerol puro como fonte de carbono no tratamento biológico de drenagem de mina.

\begin{tabular}{|c|c|c|c|c|c|c|c|c|}
\hline Remoção sulfato & $\mathrm{DQO}(\mathrm{mg} / \mathrm{L})$ & Sulfato (mg/L) & $\mathrm{pH}$ & Temp. $\left({ }^{\circ} \mathrm{C}\right)$ & Reator & TDH (h) & $\begin{array}{l}\text { AVG acumulados } \\
(\mathrm{mmol} / \mathrm{L})\end{array}$ & Referência \\
\hline $90 \%$ & 4.034 & 2.016 & 6,5 & $25-28$ & Leito fluidizado & 15 & 11 acetato e 3,3 butirato & Bertolino et al. (2014) \\
\hline $26 \%$ & 460 & 254 & 5 & 35 & $\begin{array}{c}\text { Batelada agitada } 50 \\
\text { rpm leito fixo }\end{array}$ & 50 & 1 acetato & $\begin{array}{l}\text { Santos e Johnson } \\
(2018)^{\star}\end{array}$ \\
\hline $74,8 \%$ & 6.000 & 2.000 & 5 & 34 & Frascos em batelada & 240 & NM & Matos et al. (2018)** \\
\hline $98 \%$ & 1.381 & 201 & 3 & 30 & \multirow{2}{*}{$\begin{array}{l}\text { Ascendente de leito } \\
\text { fixo Agitação } 50 \text { rpm }\end{array}$} & 125 & 2,6 acetato & \multirow{2}{*}{$\begin{array}{c}\text { Nancucheo e Johnson } \\
\text { (2014) }\end{array}$} \\
\hline $60 \%$ & 2.762 & 672 & 2,8 & 30 & & 600 & 3,1 acetato e 1,6 glicerol & \\
\hline
\end{tabular}

NM: não monitorado; DQO: demanda química de oxigênio; TDH: tempo de detenção hidráulica; *97\% de precipitação de 7,5 mmol/L de Cu. DM parcialmente clarificada esterilizada; **baixa pressão de oxigênio.

Fonte: elaborada pelas autoras (2019). 
Tabela 7 - Condições e resultados de aplicações de glicerol bruto como fonte de carbono na redução de sulfato.

\begin{tabular}{|c|c|c|c|c|c|c|c|c|}
\hline Remoção de sulfato & $\mathrm{DQO}\left(\mathrm{mg} \cdot \mathrm{L}^{-1}\right)$ & Sulfato (mg. $\left.\mathrm{L}^{-1}\right)$ & $\mathrm{pH}$ & Temp. $\left({ }^{\circ} \mathrm{C}\right)$ & Reator & TDH (h) & Oxigênio dissolvido & Referência \\
\hline $55 \%$ & NM & 900 & 7 & * & $\begin{array}{l}\text { Colunas de fluxo } \\
\text { descendente }\end{array}$ & 13 & NM & $\begin{array}{c}\text { Zamzow, Tsukamoto } \\
\text { e Miller }(2007)^{\star *}\end{array}$ \\
\hline NM & 3.600 & 3.600 & 4 & 30 & Bateladas em frascos & 720 & Anaeróbio & \multirow{2}{*}{$\begin{array}{l}\text { Santos e Johnson } \\
(2018)^{\star \star}\end{array}$} \\
\hline NM & 3.600 & 3.600 & 7 & 30 & Bateladas em frascos & 240 & Anaeróbio & \\
\hline $5,06 \mathrm{mg} / \mathrm{L} . \mathrm{h}^{-1}$ & 1540 & 220 & 8,5 & 35 & UASB & 10 & Micro-Aeróbio & $\begin{array}{c}\text { Mora, Lafuente e } \\
\text { Gabriel (2018) }\end{array}$ \\
\hline
\end{tabular}

DQO: demanda química de oxigênio; TDH: tempo de detenção hidráulica; AGV: ácidos graxos voláteis; *ambiente (inverno Estados Unidos); **a adição de nutrientes e vitaminas. Fonte: elaborada pelas autoras (2O19).

Tabela 8 - Composição de resíduos de cervejaria (massa/massa).

\begin{tabular}{l|c|c|c} 
& Trub & Grãos gastos & Levedura utilizada \\
\hline DQO (gDQO/gMF) & 0,294 & 0,289 & 0,316 \\
\hline Celulose (\%ST) & 8,2 & 1,0 & 19,4 \\
\hline Hemicelulose (\%ST) & 5,6 & 14,7 & 28,8 \\
\hline Lignina (\%ST) & 8 & 0,3 & 4,2 \\
\hline Açúcar (\%ST) & 57,4 & 38,6 & 12,4 \\
\hline Proteínas (\%ST) & 15 & 35,9 & 18 \\
\hline Lipídio (\%ST) & 3 & 3,9 & 5 \\
\hline Cinzas (\%ST) & 2,5 & 5,6 & 10 \\
\hline
\end{tabular}

DQO: demanda química de oxigênio; MF: matéria fresca; ST: sólidos totais. Fonte: Perimenis et al. (2018).

Em suma, o cenário atual sobre o tratamento de DM mostra que existem opções de doadores de elétrons que podem tornar o tratamento mais eficiente e sustentável, como subprodutos da indústria e da agricultura, resíduos e efluentes urbanos. Porém, para que a prática seja efetivada com eficiência, lacunas devem ser preenchidas:

- Como o sistema biológico de tratamento responde às variações temporais na composição da DM;

- Como o consórcio microbiano responde frente aos diferentes substratos mistos quanto à produção, ao consumo e ao consequente acúmulo de ácidos graxos voláteis;

- Os parâmetros ideais para cada tipo de substrato, dos quais o mais desconhecido é o efeito de baixas concentrações de oxigênio. Embora já tenha sido investigada a influência da relação $\mathrm{DQO} / \mathrm{SO}_{4}{ }^{2-}$, esse parâmetro deve ser melhor estudado individualmente, para cada tipo de substrato misto;

- Qual é a eficiência do tratamento biológico de DM usando GB como fonte de carbono?;

- Qual é a eficiência do tratamento biológico de DM usando resíduos de cervejaria como fonte de carbono?;

- Qual o TDH para redução de sulfato perante cada tipo de substrato utilizado?

- Respondendo a essas questões, o uso de resíduos e efluentes orgânicos pode se tornar um destino adequado a eles e uma forma de melhorar a eficiência do tratamento de DM.

As informações concentradas nesta revisão podem nortear a projeção de sistemas de tratamento de DM mais sustentáveis, se observados também a logística e o contexto do local de aplicação. Ainda na busca para bons resultados do sistema em escala plena, ressalta-se a lacuna de conhecimento sobre formação e destino de subprodutos e polimento do efluente final. Demanda-se avaliar se, a longo prazo, a mistura de DM com a fonte de carbono não provocará imobilização por precipitação de macro e micronutrientes essenciais, afetando a comunidade microbiológica de interesse.

\section{CONTRIBUIÇÕES DOS AUTORES}

Vieira, B. F.: Conceituação, Investigação, Escrita - Primeira Redação. Araújo, J. C.: Obtenção de Financiamento, Supervisão, Validação, Escrita - Revisão e Edição. Teixeira, M. C.: Supervisão, Validação, Escrita - Revisão e Edição. Pereira, J. C. S.: Investigação, Escrita - Primeira Redação.

\section{REFERÊNCIAS}

ALBUQUERQUE, M.F.G. Tratamento do glicerol bruto proveniente da produção de biodiesel visando a geração de metano. 98f. Dissertação (Mestrado em Biotecnologia) - Universidade Federal de Ouro Preto, Ouro Preto, 2014.

BEAULIEU, S.; ZAGURY, G.J;; DESCHENES, L.; SAMSON, R. Bioactivation and bioaugmentation of a passive reactor for acid mine drainage treatment. In: SINGHAL, R.K.; MEHROTRA, A.K. (org.). Environmental issues and management of waste in energy and mineral production. Roterdã: Balkema, 2000. p. 533-537.

BEHROOZ, M.; BORDEN, R.C. Waste Glycerol Addition to Reduce AMD Production in Unsaturated Mine Tailings. Mine Water and the Environment, v. 31, n. 3, p. 161-171, 2012. https://doi.org/10.1007/s10230-012-0180-x
BERTOLINO, S.M.; MELGAÇO, L.A.; SÁ, R.G.; LEÃO, V.A. Comparing lactate and glycerol as a single-electron donor for sulfate reduction in fluidized bed reactors. Biodegradation, v. 25, n. 5, p. 719-733, 2014. https://doi.org/10.1007/s10532-014-9694-1

BERTOLINO, S.M.; RODRIGUES, I.C.B.; GUERRA-SÁ, R.; AQUINO, S.F.; LEÃO, V.A. Implications of volatile fatty acid profile on the metabolic pathway during continuous sulfate reduction. Journal of Environmental Management, v. 103, p. 15-23, 2012. https://doi.org/10.1016/j.jenvman.2012.02.022

CORBETT, C. Development of the Rhodes BioSURE Process in the treatment of acid mine drainage wastewaters. Dissertação (Mestrado) Rhodes University, Africa do Sul, 2001. 
CUNHA, M.P.; FUESS, L.T.; RODRIGUEZ, R.P.; LENS, P.N.L.; ZAIAT, M. Sulfidogenesis establishment under increasing metal and nutrient concentrations: An effective approach for biotreating sulfate-rich wastewaters using an innovative structured-bed reactor (AnSTBR). Bioresource Technology Reports, v. 11, 100458, 2020. https://doi.org/10.1016/j. biteb.2020.100458

DEV, S.; ROY, S.; BHATTACHARYA, L. Optimization of the operation of packed bed bioreactor to improve the sulfate and metal removal from acid mine drainage. Journal of Environmental Management, v. 200, p. 135-144, 2017. https://doi.org/10.1016/j.jenvman.2017.04.102

HAO, T.; XIANG, P.; MACKEY,H.R.; CHI, K.; LU, H.; CHUI,H.-K.; VANLOOSDRECHT, M.C.M.; CHEN, G.H. A review of biological sulfate conversions in wastewater treatment Water Research, v. 65, p. 1-21, 2014. https://doi.org/10.1016/j. watres.2014.06.043

HEDRICH, S.; JOHNSON, D.B. Remediation and Selective Recovery of Metals from Acidic Mine Waters Using Novel Modular Bioreactors. Environmental Science and Technology, v. 48, n. 20, p. 12206-12212, 2014. https://doi. org/10.1021/es5030367

HU, Y.; JING, Z:; SUDO, Y.; NIU, Q.; DU, J.; WU, J.; LI, Y. Effect of influent $\mathrm{COD} / \mathrm{SO} 42$ - ratios on UASB treatment of a synthetic sulfate-containing wastewater. Chemosphere, v. 130, p. 24-33, 2015. https://doi.org/10.1016/j. chemosphere.2015.02.019

HUSSAIN, A.; QAZI, J.I. Application of sugarcane bagasse for passive anaerobic biotreatment of sulphate rich wastewaters. Applied Water Science, v. 6. p. 205-211, 2016. https://doi.org/10.1007/s13201-014-0226-2

JAMIL, I.N.; CLARKE, W.P. Bioremediation for acid mine drainage: organic solid waste as carbon sources for sulfate-reducing bacteria: a review. Journal of Mechanical Engineering and Sciences, v. 5, p. 569-581, 2013. http://doi.org/10.15282/jmes.5.2013.3.0054

KEFENI, K.K.; MSAGATI, T.A.M.; MAMBA, B.B. Acid mine drainage: Prevention, treatment options, and resource recovery: A review. Journal of Cleaner Production, v. 151, p. 474-493, 2017. https://doi.org/10.1016/j. jclepro.2017.03.082

KJELDSEN, K.U.; JOULIAN, C.; INGVORSEN, K. Oxygen Tolerance of Sulfate-Reducing Bacteria in Activated Sludge. Environmental Science and Technology, v. 38, n. 7, p. 2038-2043, 2004. https://doi.org/10.1021/ esO34777e

KUMAR, P.; SHARMA, R.; RAY, S.; MEHARIYA, S.; PATEL, S.K.S.; LEE, J.K.; KALIA, V.C. Dark fermentative bioconversion of glycerol to hydrogen by Bacillus thuringiensis. Bioresource Technology, v. 182, p. 383-388, 2015. https://doi. org/10.1016/j.biortech.2015.01.138

KUMAR, R.N.; MCCULLOUGH, C.D.; LUND, M.A.; NEWPORT, M. Sourcing Organic Materials for Pit Lake Bioremediation in Remote Mining Regions. Mine Water and the Environment, v. 30, n. 4, p. 296-301, 2011. https://doi. org/10.1007/s10230-011-0144-6

LIN, S.; MACKEY, H.R.; HAO, T.; GUO, G.; VAN LOOSDRECHT, M.C.M.; CHEN, G. Biological sulfur oxidation in wastewater treatment: A review of emerging opportunities. Water Research, v. 143, p. 399-415, 2018. https://doi. org/10.1016/j.watres.2018.06.051

MARTINS, M.; SANTOS, E.S.; PIRES, C.; BARROS, R.J.; COSTA, M.C. Production of irrigation water from bioremediation of acid mine drainage: comparing the performance of two representative systems. Journal of Cleaner Production, v. 18, n. 3, p. 248-253, 2010. https://doi.org/10.1016/j.jclepro.2009.10.013
MATOS, L.P.; COSTA, P.F.; MOREIRA, M.; MOREIRA, M.; GOMES, P.C.S.; SILVA, S.Q.; GURGEL, L.V.A.; TEIXEIRA, M.C. Simultaneous removal of sulfate and arsenic using immobilized non-traditional SRB mixed culture and alternative low-cost carbon sources. Chemical Engineering Journal, v. 334 , p. 1630-1641, 2018. https://doi.org/10.1016/j.cej.2017.11.035

MCGREGOR, R.; BLOWES, D.W. The physical chemical and mineralogical proprieties of three cemented layers within sulfide - bearing mine tailings. Journal of Geochemical Exploration, v. 76, n. 3, p. 195-207, 2002. https://doi. org/10.1016/SO375-6742(O2)00255-8

MOCKAITIS, G.; PANTOJA, J.L.R.; RODRIGUES, J.A.D.; FORESTI, E.; ZAIAT, M. Continuous anaerobic bioreactor with fixed-structure bed (ABFSB) for wastewater treatment with low solids and low applied organic loading content. Bioprocess and Biosystems Engineering, v. 37, n. 7. p. 1361-1368, 2014. https://doi.org/10.1007/s00449-013-1108-y

MOODLEY, I.; SHERIDAN, C.M.; KAPPELMEYER, U.; AKCIL, A. Environmentally sustainable acid mine drainage remediation: Research developments with a focus on waste/by-products. Minerals Engineering, v. 126, p. 207-220, 2017. https://doi.org/10.1016/j.mineng.2017.08.008

MORA, M.; LAFUENTE, J.; GABRIEL, D. Screening of biological sulfate reduction conditions for sulfidogenesis promotion using a methanogenic granular sludge. Chemosphere, v. 210, p. 557-566, 2018. https://doi. org/10.1016/j.chemosphere.2018.07.025

MUHAMMAD, S.N.; KUSIN, F.M.; ZAHAR, M.S.M.; HALIMOON, N.; YUSUF, F.M. Passive treatment of acid mine drainage using mixed substrates: batch experiments. Procedia Environmental Sciences, v. 30, p. 157-161, 2015. https:// doi.org/10.1016/j.proenv.2015.10.028

NAGPAL, S.; CHUICHULCHERM, S.; PEEVA, L.; LIVINGSTON, A. Microbia sulfate reduction in a liquid-solid fluidized bed reactor. Biotechnology and Bioengineering, v. 70, n. 4, p. 370-380, 2000. https://doi.org/10.1002/1097O290(20001120)70:4<370:AID-BIT2>3.0.CO;2-7

ŇANCUCHEO, I.; JOHNSON, D.B. Removal of sulfate from extremely acidic mine waters using low pH sulfidogenic bioreactors. Hydrometallurgy, v. 150, p. 222-226, 2014. https://doi.org/10.1016/j.hydromet.2014.04.025

NECULITA, C.M.; ZAGURY, G. Biological treatment of highly contaminated acid mine drainage in batch reactors: Long-term and reactive mixture characterization. Journal of Hazardous Materials, v. 157, n. 2-3, p. 358-366, 2008. https://doi.org/10.1016/j.jhazmat.2008.01.002

NOGUEIRA, E.W.; LICONA, F.M.; GODOI, L.A.G.; BRUCHA G.; DAMIANOVIC, M.H.R.Z. Biological treatment removal of rare earth elements and yttrium (REY) and metals from actual acid mine drainage. Water, Science \& Technology, v. 80, n. 8, p. 1485-1493, 2019. https://doi.org/10.2166/ wst.2019.398

PERIMENIS, A.; NICOLAY, T.; LECLERCQ, M.; GERIN, P.A. Comparison of the acidogenic and methanogenic potential of agroindustrial residues. Waste Management, v. 72, p. 178-185, 2018. https://doi.org/10.1016/j. wasman.2017.11.033

PLACE, D.L.; FIGUEROA, L.; WILDEMAN, T. Characterizing and tracking reactive mixture alteration: new tools for passive treatment design and monitoring. In: ICARD, 7., 2006, St. Louis. Anais [...]. 2006. p. 25-30.

QUISPE, C.A.G.; CORONADO, C.J.R.; CARVALHO JÚNIOR, J.A. Glycerol Production, consumption, prices, characterization and new trends in combustion. Renewable and Sustainable Energy Reviews, v. 27, p. 475-493, 2013. http://doi.org/10.1016/j.rser.2013.06.017 
REIS, M.; LEMOS, P.; ALMEIDA, J.; CARRONDO, M. Influence of produced acetic acid on growth of sulfate reducing bacteria. Biotechnology Letters, $\mathrm{v}$. 12, p. 145-148, 1990. https://doi.org/10.1007/BF01022432

REISMAN, D.J.; GUSEK, J.J.; BISHOP, M. A pre treatability study to provide data for construction of a demonstration bioreactor. In: INTERNATIONAL CONFERENCE ON TAILINGS AND MINE WASTE, 10., 2003. Anais [...]. 2003. p. 305-315.

RODRIGUEZ, R.P. Aplicação de reatores anaeróbios para remoção de sulfato de águas de drenagem ácida de minas. 198f. Tese (Doutorado em Ciências) - Escola de Engenharia de São Carlos, Universidade de São Paulo, São Carlos, 2010.

RODRIGUEZ-FREIRE, R.L.; MOORE, S.E.; SIERRA-ALVAREZ, A.R.; ROOT, R.A.; CHOROVER, J.; FIELD, J.A. Arsenic remediation by formation of arsenic sulfide minerals in a continuous anaerobic bioreactor. Biotechnology and Bioengineering, v. 113, n. 3, p. 522-530, 2016. https://doi.org/10.1002/bit.25825

SÁNCHEZ-ANDREA, A.I.; SANZ, J.L.; BIJMANS, M.F.M.; STAMS, A.J.M. Sulfate reduction at low pH to remediate acid mine drainage. Journal of Hazardous Materials, v. 269, p. 98-109, 2014. https://doi.org/10.1016/j.jhazmat.2013.12.032

SANTOS, A.L.; JOHNSON, D.B. Design and application of a low pH upflow biofilm sulfidogenic bioreactor for recovering transition metals from synthetic waste water at a Brazilian copper mine. Frontiers in Microbiology, v. 9, p. 2051, 2018. https://doi.org/10.3389/fmicb.2018.02051

SANTOS, A.L.; JOHNSON, D.B. The effects of temperature and $\mathrm{pH}$ on the kinetics of an acidophilic sulfidogenic bioreactor and indigenous microbial communities. Hydrometallurgy, v. 168, p. 116-120, 2017. https://doi. org/10.1016/j.hydromet.2016.07.018

SANTOS, S.C.; LIEBENSTEINER, M.G.; SOUZA, L.C.S.V; RAMOS, C.L.S.; BATISTA, L.L.F.; MATOS, J.B.T.L.; QUINTELLA, C.M.; ALMEIDA, P.F. Crude Glycerol as a Substrate for Sulfate-reducing Bacteria from a Mature Oil Field and its Potential Impact on Souring. Journal of Petroleum Science and Technology, v. 5, n. 1, p. 1-9, 2015.

SERRANO, A.; PECES, M.; ASTALS, S.; VILLA-GÓMEZ, D.K. Batch assays for biological sulfate-reduction: a review towards a standardized protocol. Critical Reviews in Environmental Science and Technology, v. 50, n. 12, p. 1195-1223, 2020. https://doi.org/10.1080/10643389.2019.1644103

SILVA, A.J.; VARESCHE, M.B.; FORESTI, E.; ZAIAT, M. Sulphate removal from industrial wastewater using a packed-bed anaerobic reactor. Process Biochemistry, v. 37, n. 9, p. 927-935, 2002. https://doi.org/10.1016/S00329592(01)00297-7
SILVAS, S.P.C.; BUZZI, D.C.; BERNARDES, A.M.; ESPINOA, D.C.R.; TENÓRIO, J.A.S. Caracterização e neutralização de drenagens ácidas de minas provenientes da mineração de carvão em Santa Catarina. Revista Brasileira de Ciências Ambientais, n. 20, p. 23-32, 2011.

SIMATE, G.S.; NDLOVU, S. Acid mine drainage: Challenges and opportunities. Journal of Environmental Chemical Engineering, v. 2, n. 3, p. 1785-1803, 2014. https://doi.org/10.1016/j.jece.2014.07.021

SKOUSEN, J.; ZIPPER, C.E.; ROSE, A.; ZIEMKIEWICZ, P.F.; NAIRN, R.; MCDONALD, L.M.; KLEINMANN, R.L. Review of passive systems for acid mine drainage treatment. Mine Water and the Environment, v. 36, n. 1, p. 133-153, 2017. https://doi.org/10.1007/s10230-016-0417-1

SMYNTEK, P.M.; CHASTEL, J.; PEER, R.A.M.; ANTHONY, E.; MCCLOSKEY, J.; BACH, E.; WAGNER, R.C.; BANDSTRA, J.Z.; STROSNIDER, W.H.J. Assessment of sulphate and iron reduction rates during reactor start-up for passive anaerobic cotreatment of acid mine drainage and sewage. Geochemistry: Exploration, Environment, Analysis, v. 18, n. 1, p. 76-84, 2018. https://doi. org/10.1144/geochem2017-001

VIEIRA, B.F.; COUTO, P.T.; SANCINETTI, G.P.; KLEIN, B.; ZYL, D.; RODRIGUEZ, R.P. The effect of acidic $\mathrm{pH}$ and presence of metals as parameters in establishing a sulfidogenic process in anaerobic reactor. Journal of Environmental Science and Health, v. 51, n. 10, p. 793-797, 2016. https://doi.or g/10.1080/10934529.2016.1181433

WEBER, P.A.; WEISENER, C.G.; DILORETO, Z. Passive Treatment of ARD Using Mussel Shells - Part I: System Development and Geochemical Processes. In: INTERNATIONAL CONFERENCE ON ACID ROCK DRAINAGE AND IMWA ANNUAL CONFERENCE, 10., Santiago, 2015. Anais [...]. 2015. p. 21-24.

WENDT-POTTHOFF, K.; NEU, T.R. Microbial processes for potential in situ remediation of acidic lakes. In: GELLER, W.; KLAPPER, H.; SALOMONS, W. (org.). Acidic mining lakes. Berlim: Springer, 1998. p. 269-284.

WU, J.; LU, J.; CHEN, T.; HE, Z.; SU, Y.; JIN, X.; YAO, X. In situ biotreatment of acidic mine drainage using straw as sole substrate. Environmental Earth Sciences, v. 60, p. 421-429, 2010. https://doi.org/10.1007/s12665-009-0186-2

ZAMZOW, K: TSUKAMOTO, T.K: MILLER, G.C. Biodiesel waste fluid as inexpensive carbon source for bioreactors treating acid mine drainage. In: IMWASYMPOSIUM: WATER IN MINING ENVIRONMENTS, 2007, Cagliari. Anais [...]. 2007.

ZHANG, M.; WANG, H. Preparation of immobilized sulfate reducing bacteria (SRB) granules for effective bioremediation of acid mine drainage and bacterial community analysis. Minerals Engineering, v. 92, p. 63-71, 2016. https://doi.org/10.1016/j.mineng.2016.02.008 